\title{
EXPERIÊNCIA DE OFERTA DE DISCIPLINA NA MODALIDADE EAD EM CENTRO UNIVERSITÁRIO DE SANTA CATARINA
}

\author{
BRUSQUE/SC MAIO/2018
}

\author{
Joel Haroldo Baade - UNIFEBE - baadejoel@unifebe.edu.br \\ Fabiani Cervi Colombi - UNIFEBE - fabicolombi@unifebe.edu.br \\ Heloisa Maria Wichern Zunino - UNIFEBE - helo@unifebe.edu.br \\ Quésia Cabral Martins - UNIFEBE - quesiacabral.m@gmail.com
}

Tipo: Relato de Experiência Inovadora (EI)
Categoria: Métodos e Tecnologias
Setor Educacional: EDUCAÇÃO SUPERIOR

RESUMO

A educação a distância (EAD) passou por constante expansão no Brasil nas últimas décadas. As instituições que tradicionalmente eram contrárias à modalidade cada vez mais se inserem na nova realidade da $E A D$, passando a ofertar disciplinas na modalidade $E A D$ em seus cursos de graduação presenciais no limite de até vinte por cento. Esta análise ocupa-se com o perfil de estudantes da disciplina de Metodologia Científica ofertada pela primeira vez na modalidade a distância em 2017 em um Centro Universitário de Santa Catarina. A pesquisa tem caráter exploratório. A metodologia consistiu na aplicação de questionário a 428 estudantes através do ambiente virtual de ensino e aprendizagem (AVEA), contemplando questões de múltipla escolha e um espaço para comentários. Conclui-se que os estudantes têm acesso às tecnologias empregadas pela instituição no desenvolvimento da disciplina, mas poucos possuem desenvolvidas as competências essenciais para o estudo a distância, tais como autonomia, disciplina e fluência em leitura, interpretação e escrita de textos, comprometendo as possibilidades de aprovação na disciplina.

Palavras-chave: Educação a Distância. Presencialidade. Perfil de estudantes. 20\% cursos presenciais. 


\section{Introdução}

A educação a distância (EAD) passou por constante expansão no Brasil nas últimas décadas. As instituições que tradicionalmente eram contrárias à modalidade cada vez mais se inserem na nova realidade da $E A D$, passando a ofertar disciplinas na modalidade EAD em seus cursos de graduação presenciais no limite de até vinte por cento, conforme estabelecidos pela Portaria MEC nำ1134, de 10 de outubro de 2016. A inserção de disciplinas integralmente a distância, além de tornar o currículo mais flexível e alinhado com tecnologias de informação, traz outros impactos positivos como: otimização dos espaços físicos; compartilhamento de material entre docentes; desenvolvimento da aprendizagem autônoma dos estudantes; possibilidade do estudante gerir a aprendizagem ao seu próprio ritmo; monitoramento e evolução da aprendizagem do estudante; diversificação das estratégias pedagógicas dos docentes; redução de custos a longo prazo. A instituição em que se realizou o presente pesquisa é um centro universitário de Santa Catarina, com aproximadamente três mil estudantes. Até 2016, vinte por cento da cada disciplina era realizada na modalidade a distância. Em 2017, optou-se pela oferta de algumas disciplinas totalmente a distância e as demais totalmente presenciais. A partir disso, esta análise ocupa-se com o perfil e percepção de estudante da disciplina de Metodologia Científica ofertada pela primeira vez na modalidade a distância em 2017. A oferta foi marcada por índice de reprovação de dezessete por cento, de um total de 428 estudantes. A pesquisa tem caráter exploratório. A metodologia consistiu na aplicação de questionário aos estudantes através do ambiente virtual de ensino e aprendizagem (AVA), contemplando questões de múltipla escolha e um espaço para comentários.

\section{Referencial teórico}

Atualmente, negar a Educação a Distância pode representar falta de visão estratégica dos gestores universitários, uma vez que os números da EAD no Brasil demonstram um crescimento exponencial no número de matrículas para essa modalidade de ensino. Compreender a sua evolução e os impactos sobre o ensino superior, requer acompanhar o movimento da EAD com atenção e estudo aprofundado. No estudo da história da EAD, é importante compreender as mudanças ocorridas na oferta desta modalidade de ensino, desde a sua implantação até a sua contemporaneidade. Segundo Huebner e Wiener (2001 apud CORTELAZZO, 2013), inicialmente, o termo ensino a distância faz alusão a Anna Ticknor que, em 1873, promoveu a educação por correspondência, em Boston (EUA). Ticknor definia o assunto, organizava e enviava o material impresso para 10 mil mulheres. A partir de 1920, aconteceram avanços na divulgação do ensino via radiodifusão. Esse acesso continuou evoluindo por outros 
meios, como por exemplo "[...] por teleeducação (décadas de 1950, 1960 e 1970), por satélite e por teleconferência (décadas de 1980 e 1990) [...]". (JÓNASSON, 2001 apud CORTELAZZO, 2013, p. 38). Em cada momento, o foco foi a promoção do aprendizado. Adentrando o século XXI, a EAD foi revolucionada pela evolução dos sistemas de comunicação mediados por computador. Os recursos tecnológicos permitiram a socialização e a facilitação da aprendizagem, por meio de "[...] encontros entre tutores (orientadores) e aprendizes disponíveis em videoconferência, o que possibilita um contato face a face em tempo real (tutor-orientador e aprendiz)" (DOXSEY, 2017, p. 107).

Não há um consenso entre os autores acerca da diferenciação entre ensino a distância e educação a distância. Segundo Maia e Mattar, "[... ] a sigla EAD é aplicada a atividades de ensino e aprendizagem em que o aluno e professor estão separados fisicamente" (MAIA; MATTAR, 2007, p. 6). O ensino a distância pode ser compreendido como uma das faces da Educação. Já a educação a distância apresenta-se como um processo de ensino/aprendizagem que acontece por meio da mediação do professor, em um ambiente virtual de aprendizagem, em que é disponibilizado o ensino por meio de elementos tecnológicos: chats, videoaulas, fóruns, biblioteca virtual, além do livro didático online.

No Brasil, diante do crescimento e procura pela EAD, iniciam-se as discussões para a sua regulamentação. Marco importante nesse sentido é a Lei no 9.394/1996 (LDB), que prevê a modalidade em todos os níveis de ensino. A regulamentação da EAD ocorre subsequentemente através dos decretos № 2.494/1998 e a sua retificação pelo decreto no 5.622/2005 do Ministério da Educação (MEC), no qual se estabelece: "A Educação a Distância é a modalidade educacional na qual a mediação didático-pedagógica nos processos de ensino e aprendizagem ocorre com a utilização de meios e tecnologias de informação e comunicação, com estudantes e professores desenvolvendo atividades educativas em lugares ou tempos diversos." Diante disso, as instituições de ensino superior (IES) no Brasil passaram a oferecer percentual de seus cursos de graduação à distância, observando especialmente o estabelecido na Portaria MEC nำ1.134, de 10 de outubro de 2016. Nos últimos anos, a Educação a Distância no Brasil apresentou um crescimento acelerado no número de matrículas como consequência do grande avanço das tecnologias da informação e comunicação que permite ao acadêmico estudar aonde ele estiver, desde que esteja conectado. Tanto quanto a evolução no número de matrículas e dos recursos tecnológicos que viabilizam a EAD, ela também passou, ao longo dos anos, por mudanças nos seus processos de regulação e mais recentemente, em 2017, com a publicação do Novo Marco Regulatório da EAD - Portaria Normativa no 11, de 20 de junho de 2017. O Novo Marco a princípio não traz mudanças tão 
significativas no âmbito da regulação, para tanto, permite uma ampliação enorme no números de matrículas, com a abertura na legislação para a criação de novos polos.

Elemento fundamental para o desenvolvimento de atividades a distância alinhadas às tendências recentes é o AVA. Sendo possível, por intermédio dele, a possibilidade criativa de apresentar conteúdos e atividades que despertem nos estudantes o desejo de aprender e a superação da questão da "presencialidade". Para Behar e Waquil, o AVA é caracterizado pela mobilidade e alinearidade, possibilitando romper com a dimensão temporal/espacial do ambiente presencial de aprendizagem (BEHAR; WAQUIL, 2009). Em relação à primeira característica, a mobilidade "permite uma flexibilidade, que proporciona que não haja rigidez de horário para acessar as funcionalidades do ambiente e para permanecer nelas, assim como não há rigor na decisão de usar determinados espaços para a interação" (BEHAR; WAQUIL, 2009, p.150). Já em relação à segunda, a alinearidade "possibilita o acesso ao AVA em qualquer tempo, em qualquer lugar e em qualquer ordem. Além disso, o percurso a ser realizado por cada sujeito é único, não havendo um caminho rígido a ser seguido" (BEHAR; WAQUIL, 2009, p. 151).

\section{Metodologia}

A Pesquisa teve natureza aplicada, com abordagem qualitativa e quantitativa, do tipo descritiva. Quanto aos procedimentos técnicos, a pesquisa pode ser caracterizada como sendo do tipo levantamento (survey). O universo da pesquisa consistiu em quatrocentos e vinte e oito (428) estudantes de graduação de uma IES de Santa Catarina matriculados na disciplina de Metodologia Científica, com carga horária de trinta (30) horas. A Coleta de dados ocorreu por meio de um questionário eletrônico construído no próprio AVA da instituição e disponibilizado aos estudantes na sala virtual da disciplina frequentada. O questionário foi composta de quatorze (14) questões de múltipla escolha com alternativa única; três (3) questões com a possibilidade de múltiplas alternativas e uma questão aberta para comentários. A Análise foi estatística e de conteúdo (TRIVIÑOS, 1987; BARDIN, 2011; FONSECA, 2002).

\section{Resultados e Análise}

A coleta de dados que resultou na presente análise foi realizada no primeiro semestre de 2017, na disciplina de metodologia científica, que possuía carga horária de 30 horas. Esta foi a primeira disciplina oferta na modalidade totalmente a distância na instituição sede do estudo. Da população, obteve-se uma amostra de 181 sujeitos que devolveram o questionário respondido, resultando em um intervalo de confiança de $94,5 \%$ e margem 
de erro de 5,5\%. O quadro 1 apresenta a consolidação dos resultados das dezessete (17) questões de múltipla escolha.

Quadro 1 - Resultados do questionário

\begin{tabular}{|c|c|c|c|}
\hline Questão & A Iternativa & Total absoluto & Total Percentual \\
\hline \multirow{3}{*}{ 1.Você usa e-mail da IES? } & $\operatorname{sim}$ & 100 & $88 \%$ \\
\hline & Nà̀o & 19 & $10 \%$ \\
\hline & Năo respondeu & 2 & $1 \%$ \\
\hline \multirow{4}{*}{$\begin{array}{l}\text { 2. Quantas vezes por semana vooé } \\
\text { acessa o seu email? }\end{array}$} & Menos de 1 vez & 20 & $11 \%$ \\
\hline & 1 ou 2 vezes & 55 & $30 \%$ \\
\hline & De 3 a 5 vezes & 61 & $34 \%$ \\
\hline & Mais de 5 vezes & $\begin{array}{l}44 \\
37\end{array}$ & $24 \%$ \\
\hline \multirow{4}{*}{$\begin{array}{l}\text { 3. Como vocé a valiaria o seu } \\
\text { computador pessoal? }\end{array}$} & $\begin{array}{l}\text { Regular } \\
\text { Bom }\end{array}$ & $\frac{37}{79}$ & $\frac{20 \%}{44 \%}$ \\
\hline & Insuficiente & 14 & $8 \%$ \\
\hline & Otimo & 42 & $23 \%$ \\
\hline & Năo tenho computador em casa & 7 & $4 \%$ \\
\hline \multirow{4}{*}{$\begin{array}{l}\text { 4. Qual a velocid ade da sua Internet } \\
\text { de casa? }\end{array}$} & en tre $5 \mathrm{Mbps}$ e $10 \mathrm{Mbps}$ & 40 & $22 \%$ \\
\hline & entre $1 \mathrm{Mbps}$ e $2 \mathrm{Mbps}$ & 50 & $28 \%$ \\
\hline & entre $2 \mathrm{Mbps}$ e $5 \mathrm{Mbps}$ & 46 & $25 \%$ \\
\hline & $\begin{array}{l}\text { menos de } 1 \mathrm{Mbps} \\
\text { mais de } 10 \mathrm{Mbps}\end{array}$ & $\begin{array}{l}19 \\
24\end{array}$ & $\begin{array}{l}10 \% \\
13 \%\end{array}$ \\
\hline \multirow{3}{*}{$\begin{array}{l}\text { 5. Que tipo de telét ne celular vock } \\
\text { possui?? }\end{array}$} & Smartphone & $\frac{27}{185}$ & $91 \%$ \\
\hline & Celular convencional & 14 & $8 \%$ \\
\hline & Năo possuo celular & 1 & $1 \%$ \\
\hline \multirow{3}{*}{$\begin{array}{l}\text { 6. Vook̂ acessa a internet com o } \\
\text { celulur? }\end{array}$} & Dados móveis/Wif & 129 & $71 \%$ \\
\hline & Apenas Wifi & 49 & $27 \%$ \\
\hline & Náo acesso & 2 & $1 \%$ \\
\hline \multirow{3}{*}{$\begin{array}{l}\text { 7.As mensagens via SMS da IES no } \\
\text { seu celular ajudaram a lembrar dos } \\
\text { prazos? }\end{array}$} & $\begin{array}{l}\text { não, já havia feito as atividade antes } \\
\text { năo recebi mensagem SMS da IES }\end{array}$ & $\begin{array}{l}33 \\
84\end{array}$ & $\begin{array}{l}18 \% \\
35 \%\end{array}$ \\
\hline & sim, pois tinha esquecido o compro misso & 75 & $41 \%$ \\
\hline & pre fro năo receber mensagens SMS da IES & 8 & $4 \%$ \\
\hline \multirow{3}{*}{$\begin{array}{l}\text { 8. Qual a forma de acesso uflizada } \\
\text { para as disciplinas da IES? }\end{array}$} & Navegador de internet & 143 & $79 \%$ \\
\hline & Aplicativo do Moodle & 37 & $20 \%$ \\
\hline & na tela do computador & 45 & $25 \%$ \\
\hline \multirow{2}{*}{$\begin{array}{l}\text { 9.Você tem o hábito de fazer suas } \\
\text { leituras em quais disposifvos? }\end{array}$} & no tablet & 1 & $1 \%$ \\
\hline & $\begin{array}{l}\text { no celular } \\
\text { impresso }\end{array}$ & $\begin{array}{l}18 \\
40\end{array}$ & $\begin{array}{l}10 \% \\
22 \%\end{array}$ \\
\hline \multirow{6}{*}{$\begin{array}{l}\text { 10. Que tipo de conteúdo/páginas } \\
\text { vocế mais a cessa na in ternet? }\end{array}$} & Redes sociais (Facebo ok, LinkedIN, In stagram) & 132 & $73 \%$ \\
\hline & Videos (Youtube, Netflix Vimeo) & 99 & $55 \%$ \\
\hline & Fóruns & 18 & $10 \%$ \\
\hline & Noticias & 73 & $40 \%$ \\
\hline & E-mail & 135 & $75 \%$ \\
\hline & Jogos & 22 & $12 \%$ \\
\hline \multirow{3}{*}{$\begin{array}{l}\text { 11.Em média, quan tas horas } \\
\text { semanais você dedicou à disciplina } \\
\text { de Metodologia Cientifica EAD? }\end{array}$} & 1 hora por semana ou men os & 58 & $32 \%$ \\
\hline & ente 1 e 2 hor as por semana & 89 & $49 \%$ \\
\hline & mais de 2 hor as por semana & 33 & $18 \%$ \\
\hline \multirow{5}{*}{$\begin{array}{l}\text { 12. Qual foi o meio mais utilizado para } \\
\text { tirar dúvidas? }\end{array}$} & Mensagens no Ambiente Virtual & 34 & $19 \%$ \\
\hline & E-mail & 21 & $12 \%$ \\
\hline & Năo five dúvidas & 68 & $38 \%$ \\
\hline & $\begin{array}{l}\text { Telefone } \\
\text { Năo encontrei a ferramenta para tirar minhas dúvidas }\end{array}$ & $\begin{array}{c}7 \\
23\end{array}$ & $\begin{array}{l}4 \% \\
13 \%\end{array}$ \\
\hline & Presencial no setor de EAD & 9 & $5 \%$ \\
\hline \multirow{4}{*}{$\begin{array}{l}\text { 13.Como vocé avalia o tempo de } \\
\text { resposta das suas dúvidas pelo } \\
\text { pro essor? }\end{array}$} & Bom & 88 & $49 \%$ \\
\hline & Otmo & 50 & $28 \%$ \\
\hline & Regular & 21 & $12 \%$ \\
\hline & Insuficiente & 4 & $2 \%$ \\
\hline \multirow{4}{*}{$\begin{array}{l}\text { 14. Como você avalia o tempo de } \\
\text { resposta das suas dúvidas pelo } \\
\text { NEAD? }\end{array}$} & Bom & 104 & $57 \%$ \\
\hline & Otmo & 31 & $17 \%$ \\
\hline & Regular & 26 & $14 \%$ \\
\hline & Insuficiente & 3 & $2 \%$ \\
\hline & Exigente & 63 & $35 \%$ \\
\hline & Pouco exigente & 8 & $4 \%$ \\
\hline 15. Em relaçao ao sistema de & Na medida certa & 68 & $36 \%$ \\
\hline & Muito exigente & 35 & $19 \%$ \\
\hline & Fraco & 5 & $3 \%$ \\
\hline & Bom & 90 & $50 \%$ \\
\hline org anizaçá o do s icones, links e & $\begin{array}{l}\text { Otmo } \\
\text { Regular }\end{array}$ & $\frac{57}{27}$ & $31 \%$ \\
\hline & Insufciente & 8 & $3 \%$ \\
\hline & Bate-papo & 25 & $14 \%$ \\
\hline & Mais questóes dissertativas & 11 & $6 \%$ \\
\hline 17. Que recursos vocé considera que & A fividades em estlo jogo & 22 & $12 \%$ \\
\hline poderiam melhorar a sua experiencia & Mais exercicios no modelo ENADE & 24 & $13 \%$ \\
\hline & Videoconferência & 11 & $8 \%$ \\
\hline & Comunicacăo ata vés das redes so cia is & 12 & $7 \%$ \\
\hline
\end{tabular}


Fonte: os autores (2018).

O principal meio de comunicação com os estudantes utilizado pela instituição em tela foi o e-mail. A instituição é signatária dos serviços Google, de modo que todos os estudantes da instituição possuem e-mail institucional acessado pela interface Gmail. Além disso, a instituição utiliza o Modular Object Oriented Distance Learning (Moodle) como ambiente virtual, de modo que a interação e comunicação com estudantes é enviada também por e-mail. Ou seja, o acesso à informação está atrelada ao acesso ao e-mail e/ou ao AVEA. A pesquisa mostrou que um percentual significativo de estudantes (41\%) não acessa o e-mail institucional ou então acessa ele menos de 2 vezes por semana, embora este ainda seja considerado um dos tipos de conteúdos mais acessados na internet (73\%). Pode-se concluir a partir disso que a eficácia do e-mail como meio de comunicação com o estudante que realiza disciplina na modalidade a distância pode não ser a maneira mais eficaz de comunicação. A isso deve-se somar os $58 \%$ de estudantes que não responderam ao questionário, sendo que a sua divulgação ocorreu preponderantemente pelos fóruns do próprio ambiente virtual, cujas mensagens foram enviadas em cópia para os e-mails institucionais dos estudantes.

A análise dos resultados da questão o 01, corroboram com Monereo e Pozo (2010), que conceituam dois tipos de pessoas na era das Tecnologias da Informação e Comunicação: os nativos digitais e os imigrantes digitais. Os nativos digitais já estão inseridos no universo das tecnologias, e não encontram dificuldades para interagir, já enquanto que os imigrantes digitais precisam se adaptar e apropriar das ferramentas digitais, como por exemplo, ler na tela do computador. No ambiente virtual, para os estudantes nativos digitais, o uso de chats facilita a troca de informações ou esclarecimentos de dúvidas entre professor e estudante, já que o uso de emoticons sintetiza a ideia. Para o imigrante digital, a comunicação via e-mail é realizada com mais tranquilidade (MONEREO; POZO, 2010).

A infraestrutura de acesso à internet parece não ter sido empecilho para acesso à informação relativa à disciplina, considerando que $96 \%$ dos respondentes possuem computador em casa e, destes, 92\% o consideram suficiente para a realização das tarefas do dia a dia. $\mathrm{O}$ acesso residencial à internet também pode ser considerado muito bom, pois $85 \%$ dos respondentes possuem conexões com velocidade superior a $1 \mathrm{Mbps}$ e $35 \%$ tem conexão superior a $5 \mathrm{Mbps}$.

A pesquisa mostrou que os estudantes que realizaram a disciplina de Metodologia Científica na instituição no primeiro semestre de 2017 possuem smartphone (91\%) e $98 \%$ deles acessa a internet através do dispositivo. Os principais conteúdos acessados 
na internet são redes sociais, vídeos, notícias, redes sociais e e-mail, mas não necessariamente o e-mail institucional. Em geral é um jovem que não é de elaborar muitos questionamentos (36\%) e, caso tenha alguma dúvida, preferir meios síncronos para a sua resolução. Os estudantes também avaliam positivamente a resolução rápida de suas dúvidas. A experiência mostrou inclusive que, em algumas ocasiões, postava-se as mensagens no ambiente virtual e, em seguida, ligava-se no setor de educação a distância na busca da resolução. A característica do estudante é a busca de soluções rápidas para os seus problemas, sem necessidade de tempo de espera. Isso, aliás, está em conformidade com as reflexões de Bauman (2007) sobre a fugacidade característica da sociedade contemporânea.

A fugacidade do grupo de estudantes também pode ser caracterizada pelo pouco tempo dedicado à disciplina na semana. $81 \%$ dos estudantes dedicaram menos de duas (2) horas semanais à realização das atividades, o que está muito aquém do esperado, sendo que o ideal projeto foi de quatro (4) horas semanais. A aparente "pressa" para resolver a "questão da disciplina" também se reflete na pouco expectativa em relação a recursos que eventualmente pudessem melhor a experiência no AVA. Para $81 \%$ dos participantes, o AVA é bom ou ótimo e apenas $27 \%$ consideram que ferramentas melhores de chat ou exercícios com questões no modelo operatório (padrão ENADE) poderiam melhor a sua experiência na disciplina no AVA.

A finalidade do ensino no AVA é oportunizar a autonomia do estudante, tornando-o protagonista do seu aprendizado. A aprendizagem é facilitada pela organização do conteúdo e pelos diferentes meios educativos, mediado pelo professor, possibilitando assim uma aprendizagem eficaz (MAURI;ONRUBIA, 2010). "Este aprendiz é ativo e usa uma diversidade de meios para aplicar, modificar e transferir estes conteúdos, tornandose sujeito mesmo de uma construção integradora de novos conhecimentos relevantes para sua aprendizagem" (DOXSEY, 2017, p.111). O estudante, como protagonista da sua aprendizagem, tem a seu dispor uma gama de recursos digitais que poderiam ser melhor aproveitados em tempo hábil.

No espaço que os estudantes tiveram para manifestarem livremente os seus comentários, pode-se identificar cinco categorias de comentários quanto à: presencialidade da disciplina; conteúdo; sistema de avaliação; uso de vídeos; e comentários gerais com elogios e críticas à modalidade. Dos 181 questionários recebidos, 45 estudantes fizeram contribuições no item comentários. O assunto mais referido pelos estudantes foi a questão da presencialidade da disciplina de Metodologia Científica, com 20 contribuições. Para o estudante do Q60: "Acho interessante a idéia do ambiente virtual, porém no meu ponto de vista a matéria de metodologia por sua 
extrema importância na vida de um acadêmico deveria ter aulas presenciais, onde o aluno poderia tirar suas dúvidas, realizando exercícios práticos na presença de um professor!" (sic!).

Os estudantes em geral identificam qualidade do curso com presencialidade. Disciplina a distância foi sinônimo de menos aprendizado para os estudantes que postaram comentários. Eles acreditam que o seu desempenho na disciplina presencial teria sido melhor e, por consequência, entendem que houve prejuízo no curso. Para alguns, a rotina de trabalho impede a dedicação à disciplina, prejudicando o rendimento, tal como referido em Q66: "Por ser uma matéria muito usada em todo o curso,deveria ser presencial, para quem trabalha o dia todo não tem chegar as 22:15 e estudar ainda para outra materia. sem tempo ao extremo!!" (sic!). Implicitamente se reconhece a necessidade de maior dedicação à disciplina a distância, sendo que na prática a dedicação semanal aos estudos permaneceu aquém do esperado. Supostamente, a presencialidade garante a dedicação à disciplina na visão dos estudantes.

A segunda questão mais comentada pelos estudantes esteve relacionada ao conteúdo da disciplina. Nesse quesito, os comentários dos estudantes estiveram preponderantemente relacionados à extensão do conteúdo, considerada superior à sua capacidade de assimilação. Q163, por exemplo, ressalta que: "havia um conteúdo imenso a ser estudado, muita informação para o aluno, um material de 104 páginas é complicado". Destacou-se ainda que as unidades de aprendizagem poderiam ser divididas em unidades menores e se empregar uma entrega de conteúdo mais fracionada, o que permitiria incremento no nível de aprendizado. Conforme Q54: "Fazer mais aulas, fracionar a matéria de uma para passar em duas, acabei antes do tempo e se tivesse sido fracionada, teria focado mais em uma parte de cada vez". Q15, por sua vez, considerou a disciplina demasiadamente teórica. A título de conclusão, depreendese que a construção da disciplina deve considerar unidades de aprendizado menores, possibilitando maior concentração em aspectos específicos, reduzindo a percepção do estudante quanto à extensão do conteúdo como um todo. As unidades também devem prever elementos que facilitem a relação do tema em foco com a prática acadêmica e profissional do estudante.

Quatro estudantes ainda manifestaram o desejo de mais videoaulas. Q80, por exemplo, refere que: "Na minha opinião, disciplinas de EAD devem ser acompanhadas de videoaulas que explicam o conteúdo e o pdf deve servir apenas de complemento." Constata-se que o texto perde relevância na EAD em comparação à imagem, especialmente em vídeo. As unidades de aprendizagem, para possibilitarem um engajamento maior dos estudantes, devem ser cada vez mais constituídas de material 
multimídia. $\mathrm{O}$ texto é apenas mais um material e dentre outros, mas não mais a base da construção do conhecimento.

Por fim, cabe mencionar que houve comentários elogiando o desenvolvimento da disciplina e a modalidade (Q46, Q81, Q94), enquanto outros criticaram a oferta de algumas disciplinas na modalidade EAD (Q28, Q67, Q76, Q175). Por outro lado, a política institucional baseia-se, entre outras questões, na convicção de que a EAD possibilita o desenvolvimento de competências essenciais ao profissional do século XXI, dentre as quais se pode elencar a autonomia e proatividade.

\section{Considerações finais}

A partir da análise, pode-se concluir que os estudantes dos cursos presenciais já podem ser caracterizados como nativos digitais. O modelo de EAD, por sua vez, ainda é muito orientado pelo perfil do imigrante digital. Nesse sentido, está entre os desafios da instituição, cada vez mais, traduzir o conhecimento para a linguagem do nativo digital, com mais material multimídia, unidade de conteúdos menores, integração de redes sociais, entre outros. Algumas ações já puderam ser aperfeiçoadas a partir da experiência inicial, tais como o uso de redes como WhatsApp e Facebook para comunicação com os estudantes. Também foram implementadas aulas presenciais de revisão em semanas anteriores a provas presenciais, mas que são transmitidas ao vivo pelo AVA e que posteriormente ficam disponíveis para serem revistas. Ainda se desenvolveu exercícios mais práticos relacionadas aos conhecimentos da disciplina. Quanto às normas técnicas, foi criado um jogo com técnica de arrastar e soltar para a elaboração de referências bibliográficas. $O$ estudante precisa ordenar um conjunto de referências em um tempo determinado para avançar nas atividades. Outras questões em avaliação são a troca de fornecedor e entrega mais fracionada de conteúdos. Enfim, o desenvolvimento de disciplinas EAD é um processo dinâmico, que carece de constante aperfeiçoamento. $O$ público dessa modalidade de ensino, especialmente os nativos digitais, é exigente e tem pressa. É preciso uma grande capacidade de IES e equipes de se renovarem e inovarem, de modo a oferecer soluções para construção de conhecimento que ao mesmo tempo promovam o engajamento e sejam eficazes. Tratase de desafio permanente!

\section{Referências}

BARDIN, Laurence. Análise de conteúdo. São Paulo: Edições 70, 2011.

BAUMAN, Z. Tempos Líquidos. Rio de Janeiro: Jorge Zahar, 2007. 
BEHAR, Patrícia Alejandra; WAQUIL, Márcia Paul. Princípios da pesquisa científica para investigar ambientes virtuais de aprendizagem sob o ponto de vista do pensamento complexo. In: BEHAR, Patrícia Alejandra (Org.). Modelos pedagógicos em educação à distância. Porto Alegre: Artmed, 2009.

COLOSSI, Nelson; BAADE, Joel Haroldo. Crise e Mudança: significado para a gestão universitária. PROFESSARE (ONLINE), Caçador, v. 4, p. 69-84, 2015.

FONSECA, J. J. S. Metodologia da pesquisa científica. Fortaleza: UEC, 2002.

TRIVIÑOS, A. N. S. Introdução à pesquisa em ciências sociais: a pesquisa qualitativa em educação. São Paulo: Atlas, 1987.

CORTELAZZO, Iolanda Bueno de Camargo. Prática Pedagógica, aprendizagem e avaliação em Educação a Distância. Curitiba: Intersaberes, 2013.

MAIA, Carmem; MATTAR, João. ABC da EaD. São Paulo: Pearson Prentice Hall, 2007.

DOXSEY, Jaime Roy. A educação centrada no aprendiz: novos rumos para a autonomia na aprendizagem a distância - ESAB 2009. In: BACELLAR, Anita (Orgs.). A psicologia humanista na prática. 3 ed. Palhoça: Unisul, 2017. p. 107-131.

MONEREO, Carles; POZO, Juan Ignacio. O aluno em ambientes virtuais: condições, perfil e competências. In: COLL. César; MONEREO, Carles (Colab). Psicologia da Educação Virtual: aprender e ensinar com as tecnologias da informação e da comunicação. Porto Alegre: Artmede, 2010. p. 97-117.

MAURI, Teresa; ONRUBIA, Javier. O professor em ambientes virtuais: perfil, condições e competências. In: COLL. César; MONEREO, Carles (Colab). Psicologia da Educação Virtual: aprender e ensinar com as tecnologias da informação e da comunicação. Porto Alegre: Artmede, 2010. p. 118-135. 